\title{
Audio Only or Video? Multimodality for Listening Comprehension
}

\author{
Menik Winiharti, Clara Herlina \\ Bina Nusantara University \\ menikwiniharti@yahoo.com
}

\begin{abstract}
Listening plays a vital role in EFL classes. With the advance of technology nowadays, teachers can use more than one means - namely multimodality - as a tool of instruction. This study is aimed to discover whether audio or video modality is more beneficial for EFL students in listening comprehension. It used the post-test control group design to measure the participants' performances with regard to the different types of modality in listening comprehension test. The participants, 50 students of English Department of a private university in Greater Jakarta area, were given two types of test: Audio listening test (ALT) and Video listening test (VLT). The analysis used quantitative method - t-test in SPSS program - which compared the results of two kinds of the test. The findings show that there is a significant difference between the results of ALT and those of VLT. It suggests that VLT provides better scores compared to ALT scores.
\end{abstract}

Keywords: listening comprehension, audio listening, video listening, multimodality

\section{INTRODUCTION}

Listening plays a vital role in the language acquisition process. However, it can be difficult for learners since the usual listening materials used in the classroom are from textbook or cassettes or CDs, all of which only rely on audio transmission. Compared to the other language skills, listening is the most frequently used language skill in the classroom (Ferris, 1998). It is used in learning grammar, vocabulary, reading and speaking. To be able to understand the materials that the teacher is teaching, students must have sufficient listening ability. There are a lot of cognitive processes going on when someone listens to something. Purdy (1997) points out that listening is the active and dynamic process of attending, perceiving, interpreting remembering and responding to the expressed (verbal and nonverbal) needs, concerns and information offered by other human beings. Moreover, Gilakjani and Ahmadi (2011) asserted that listening comprehension is an inferential process.

To overcome the monotonous instruction in listening comprehension classes, different instruction modes or modality - can be offered. The involvement of two or more modes of communication in learning a language is called multimodality. In the world of teaching and learning it means that there are various forms and resources which are able to construct the meanings of any language such as image, sound, music, gesture, speech, body posture, and many others (Jewitt, 2013). There are several materials that can give access to both audio and visual communication such as film clips on video, DVD or online watch while listen (Harmer, 2007). By watching videos, learners can see paralinguistic behaviour, how intonation matches facial expression, gestures, etc. Thus, listening can be more meaningful if learners can see how the language is used in actual situation. In other words, they have to see how the speakers actually speak the language. In this way, learners can learn the language from both audio and visual inputs.

With regard to different modes used in EFL classes, Lee (2014, p.72) proposed that "multimodal approach was effective in promoting EFL student learning. Such an approach can benefit teachers of EFL with their curriculum design." Correspondingly, Folley's study (2015) showed that students have much more opportunities to recall particular details when visual images are provided in a listening comprehension task. Moreover, Mekheimer (2011) has suggested that at university levels, improving general linguistic proficiency for EFL students can be generated by integrating videobased materials with whole language teaching of the language skills. He further proposed, "videos should also be systematically incorporated in language assessments, especially in listening and speaking tests. Computermediated learning material could also include video segments and clips to ameliorate skill acquisition" (p.28).

According to Suvorov (2009), videos may be used in English language teaching context for a range of reasons. First, seeing a situation and its participants while listening enhances situational and interactional authenticity, which may aid comprehension. Second, body language, facial expressions and gestures of speaker provide additional information to the listener. Third, with visual input, a listener can more identify the role of a speaker and the context of a situation. Finally, visual elements can activate a listener's background knowledge.

As a matter of fact, language teachers have utilized movies, TV shows and other sources of audio visual media in their teaching, especially in teaching L2 listening because as in real life speaking situations, the use of video allows the listener to process both the aural and visual information transmitted by the speakers (Wagner, 2008). However, even though video has been popularly used as teaching material in L2 classroom, it does not get the same popularity as testing material, particularly for testing listening comprehension. Wagner 
(2010) stated, "While video is commonly employed in L2 classrooms, test developers have been reluctant to use video texts on tests of L2 listening ability" (p.495). The main concern for test developers or teachers to use video in listening test is probably related to technology and practicality. He also mentioned that video listening test requires more resources to create and deliver than more traditional audio only test.

This study tries to investigate whether the use of videos in listening comprehension provides better results than that of audio only. It tries to find if there is a significant difference between the results of audio mode test and visual mode test.

\section{METHODS}

This study used post-tests only. The data were collected from 50 students of second semester of English Department of a private university in Greater Jakarta area. To measure their performances concerning the two types of modality in listening tests, the students were given two types of tests: Audio listening test (ALT) and Video listening test (VLT). The materials for the tests were selected from "TED-Ed Lessons Worth Sharing" (http://ed.ted.com). The first video is titled the language of lying and was retrieved from http://ed.ted.com/lessons/the-language-of-lying-noahzandan. It can also be accessed through youtube (https://www.youtube.com/watch?v=H0-WkpmTPrM).

The second video is titled the effect of sleep deprivation which was retrieved from http://ed.ted.com/lessons/whatwould-happen-if-you-didn-t-sleep-claudia-aguirre and can also be accessed through youtube (https://www.youtube.com/watch?v=dqONk4815vY).

Each of the tests contained 20 questions. The first test (ALT) was administered after the participants listened to the short video for 5 minutes approximately. In this kind of the test, the screen was turned off and they only listened twice to the information given. The second test (VLT) was administered after the participants listened and watched the other short video for 5 minutes approximately. In this second test, the screen was turned on and they were able to listen and watch the video twice. Afterwards, the results of the two tests were compared and analyzed quantitatively to examine the differences in the effects of ALT and VLT on the students' performances in listening comprehension. For this purpose, an SPSS program, was used to determine if there was a significant difference between the two tests results. Larson-Hall (2010) stated that when the same group is measured at two different time and the researcher wants to see if they perform better or worse at the second time, then the paired-samples t-test should be used (p.242). The test requires two hypotheses: $\mathrm{H} 0$ (null hypothesis) and $\mathrm{H} 1$ (alternate hypothesis). The null hypothesis denotes that the means of the paired population are equal $\left(\mu_{1}=\mu_{2}\right)$. On the other hand, the alternate hypothesis indicates that the paired population means are not equal $\left(\mu_{1} \neq \mu_{2}\right)$.

\begin{tabular}{|c|c|c|}
\hline Participant & ALT & VLT \\
\hline 1 & 7 & 11 \\
\hline 2 & 12 & 15 \\
\hline 3 & 10 & 16 \\
\hline 4 & 7 & 10 \\
\hline 5 & 14 & 20 \\
\hline 6 & 8 & 5 \\
\hline 7 & 11 & 18 \\
\hline 8 & 5 & 9 \\
\hline 9 & 14 & 14 \\
\hline 10 & 5 & 7 \\
\hline 11 & 6 & 11 \\
\hline 12 & 7 & 13 \\
\hline 13 & 7 & 8 \\
\hline 14 & 3 & 10 \\
\hline 15 & 11 & 18 \\
\hline 16 & 7 & 15 \\
\hline 17 & 8 & 7 \\
\hline 18 & 4 & 5 \\
\hline 19 & 8 & 8 \\
\hline 20 & 11 & 13 \\
\hline 21 & 5 & 8 \\
\hline 22 & 10 & 14 \\
\hline 23 & 12 & 16 \\
\hline 24 & 12 & 17 \\
\hline 25 & 6 & 8 \\
\hline 26 & 3 & 5 \\
\hline 27 & 4 & 12 \\
\hline 28 & 6 & 14 \\
\hline 29 & 11 & 13 \\
\hline 30 & 8 & 10 \\
\hline 31 & 4 & 9 \\
\hline 32 & 9 & 12 \\
\hline 33 & 7 & 11 \\
\hline 34 & 7 & 10 \\
\hline 35 & 5 & 13 \\
\hline 36 & 5 & 5 \\
\hline 37 & 5 & 17 \\
\hline 38 & 5 & 4 \\
\hline 39 & 11 & 15 \\
\hline 40 & 5 & 9 \\
\hline 41 & 9 & 17 \\
\hline 42 & 13 & 15 \\
\hline 43 & 4 & 8 \\
\hline 44 & 5 & 7 \\
\hline 45 & 8 & 9 \\
\hline 46 & 2 & 7 \\
\hline 47 & 9 & 8 \\
\hline 48 & 7 & 6 \\
\hline 49 & 11 & 16 \\
\hline 50 & 8 & 13 \\
\hline
\end{tabular}

Table 1. The scores resulted from ALT and VLT

\section{RESULT AND DISCUSSION}

The following table shows the total scores gained by the participants after they had ALT and VLT. 
The scores in the table were used as the data for SPSS program, specifically the paired t-test. This test was applied since the population was the same, while they were treated by two different tests. The results of the analysis using this program are shown in the following two tables. Table 2 displays the mean scores. It shows the statistical results of Audio Listening Test (ALT) and

Table 2. Mean Scores of ALT and VLT

Paired Samples Statistics

\begin{tabular}{cc}
\hline \multicolumn{2}{c}{ MeanN Std. DeviationStd. Error Mean } \\
Pair 1ALT7.62 503.043 & .430 \\
\cline { 2 - 2 } VLT11.22504.112 & .582 \\
\hline
\end{tabular}

Video Listening Test (VLT).

The table summarizes that the means of the two tests were statistically different. Out of 20 questions, the mean resulted from VLT showed better scores than that resulted from ALT: 11.22 compared to 7.62. It indicates that in average, the students have performed or comprehended better when they can listen to the audio and watch the videos at the same time. However, it was essential to further examine the results using the other table, which was applied to determine whether there was a significant difference between the performances of the students in the two tests.

Table 3 below shows the paired differences between ALT and VLT. The hypotheses applied for the test were:

H0 (null hypothesis): $\mu_{1}=\mu_{2}$. It means that the paired population means are equal.

H1 (alternate hypothesis): $\mu_{1} \neq \mu_{2}$. It means that the paired population means are not equal.

Where $\mu_{l}$ is the population mean of variable 1 (ALT), and $\mu_{2}$ is the population mean of variable 2 (VLT).

The Interval of confidence for this test was $95 \%$ which means that sigma $(\alpha)=0.05$.

Table 3. Result of Paired Samples Test

\begin{tabular}{|c|c|c|c|}
\hline \multicolumn{3}{|c|}{$\underline{\text { Paired Differences }}$} & \multirow[b]{3}{*}{ df Sig. (2-tailed) } \\
\hline & \multicolumn{2}{|c|}{$95 \%$ Confidence Interval of the Difference } & \\
\hline Mean Std. D & nStd. Error MeanLower & Upper & \\
\hline Pair 1ALT - VLT-3.6003.003 & $.425 \quad-4.454$ & -2.746 & -8.47649 .000 \\
\hline
\end{tabular}

From the table, it is shown that the mean difference was 3.6, which denoted that the VLT scores were 3.6 higher than ALT scores. It is also shown that the p-value (sig. 2tailed) $=0.00$ which was less than $\alpha=0.05$. This proved that ${ }_{1}$ did not equal to ${ }_{2}\left(l_{1} \neq 2\right)$ which suggested that the two population means were not equal, thus, the null hypothesis should be rejected. In other words, there was a statistically significant difference between the result of ALT and that of VLT.

The findings reveal that when the students were exposed to more than one modality, i.e. audio and visual, they can improve their performance compared to when they were only exposed to one modality, i.e. audio. Using audio mode only allowed students to listen so they must entirely concentrate on the sound provided. This way, they had to remember much sound-based information. Alternatively, visual mode provided students with more varied information in addition to sound - pictures, and writings or subtitles that might occur occasionally in the video. This can make students comprehend better than just listening using audio mode only.

\section{CONCLUSION}

With the advancement of technology nowadays, multimodality plays an important role in learning English as a foreign language. Students can be exposed to multiple modality so that they are able to learn the foreign language faster and better. This study has found that visual mode (VLT) has resulted in better scores than that of audio mode (ALT). Based on this result, it can be said that by watching videos students can understand better rather than listening to the audio only. Through the videos, they can perceive other kinds of information - pictures, moves, gestures and writings. The findings then suggest that the exposure more than one modality will bring students to better performance in listening comprehension. Therefore, teachers should encourage their students to learn through many kinds of modality. In addition, teachers should also be more equipped and able to incorporate the changes, especially in the technology that can be utilized to facilitate the process of teaching and learning.

Further research about ALT and VLT can be conducted to investigate the types of questions in which students perform better. The multimodality research can also be conducted with regard to other language skills, such as speaking, reading, and writing.

\section{REFERENCES}

Ferris, D. (1998). Students' view on academic aural/oral skills: A comparative needs analysis. TESOL Quarterly, 289-318

Folley, S. (2015). The effect of visual cues in listening comprehension: Pedagogical implications for nonnative speakers of English. Culminating Projects in English. Paper 39.

Gilakjani, A., \& Ahmadi, M. (2011). A study of factors affecting EFL learners' English listening comprehension and the strategies for improvement. 
Journal of Language Teaching and Research, 2 (5), 977-988.

Harmer, J. (2007). The Practice of English Language Teaching. Harlow: Pearson Longman.

Jewitt, C. (2013). Multimodal teaching and learning. In C. Chapelle, The Encyclopaedia of Applied Linguistics (pp. 1-5). Chichester: Blackwell Publishing.

Larson-Hall, J. (2010). A guide to doing statistics in second language research using SPSS. New York: Routledge.

Lee, H. C. (2014) Using an arts-integrated multimodal approach to promote English learning. English Teaching: Practice and Critique, 13 (2), 55-75.

Mekheimer, M. A.A.G. (2011). The impact of using videos on whole language learning in EFL context. Arab World English Journal, 2 (2), 5-39.

Purdy, M. (1997). What is listening? In M. Purdy, \& Borisoff, Listening in everyday life: A personal and professional approach (pp. 1-20). Lanham: University Press of America.

Suvorov, R.S. (2009). Context visuals in L2 listening test: The effects of photograph and video vs audio-only format. In C. A. Chapelle, H. G. Jun, \& I. Katz (Eds.), Developing and Evaluating Language Learning Materials (pp. 53-68). Ames: Iowa State University.

Wagner, E. (2010). The effect of the use of video texts on ESL listening test-taker performance. Language Testing 27(4), 493-513.

Wagner, E. (2008). Video listening tests: What are they measuring? Language Assessment Quarterly, 5(3), 218-243. 